\section{The tyrosine kinase receptor c-met, its cognate ligand HGF and the tyrosine kinase receptor trasducers STAT3, PI3K and RHO in thyroid nodules associated with Hashimoto's thyroiditis: an immunohisto- chemical characterization}

\author{
R.M. Ruggeri,' E.Vitarelli,' G. Barresi, ${ }^{2}$ \\ F. Trimarchi,' S. Benvenga, 'M.Trovato² \\ 'Unit of Endocrinology, Clinical- \\ Experimental Department of Medicine and \\ Pharmacology; ' 2 Department of Human \\ Pathology, University of Messina, Messina, \\ Italy
}

\section{Abstract}

Hepatocyte growth factor (HGF) exerts proliferative activities in thyrocytes upon binding to its tyrosine kinase receptor c-met and is also expressed in benign thyroid nodules as well as in Hashimoto's thyroiditis (HT).

The simultaneous expression of $\mathrm{HGF} / \mathrm{c}$-met and three trasducers of tyrosine kinase receptors (STAT3, PI3K, RHO) in both the nodular and extranodular tissues were studied by immunohistochemistry in 50 benign thyroid nodules (NGs), 25 of which associated with HT. The ligand/tyrosine kinase receptor pair HGF/c-met and the two trasducers PI3K and RHO were expressed in NGs, regardless of association with HT, with a higher positive cases percentage in HT-associated NGs compared to not HT-associated NGs $(25 / 25$ or $100 \%$ vs $7 / 25$ or $28 \%$; $\mathrm{P}<0.001)$. HGF, PI3K and RHO expression was only stromal (fibroblasts and endothelial cells), in all 32 reactive NGs, while c-met localization was consistently epithelial (thyrocyes). Immunoreactions for HGF, c-met, PI3K and RHO were also apparent in the extra-nodular tissue of HT specimens, where HGF and PI3K were expressed not only in stromal cells but also in thyrocyes along with the c-met. Finally, a positive correlation was observed between the proportion of HGF, c-met, PI3K follicular cells and the grade of lymphoid aggregates in HT. In conclusion, HGF, c-met, PI3K are much more frequently and highly expressed in HT compared to NGs, and among all NGs in those present in the context of HT. A paracrine effect of $\mathrm{HFG} / \mathrm{c}$-met on nodule development, based on the prevalent stromal expression, may be suggested along with a major role of HGF/c-met and PI3K in HT. Finally, the expression of such molecules in HT may be regulated by lymphoid infiltrate.

\section{Introduction}

Hashimoto's thyroditis (HT) is the most prevalent autoimmune thyroid disease worldwide and is characterized by variable clinical presentation with respect to proliferation of the follicular cells. ${ }^{1,2}$ Thyrocyte proliferation may be very intense in HT, thus leading to multiple nodular lesions. ${ }^{3-6}$ Increased prevalence of HT patients with associated nodular goiter remains high in moderately iodine-deficient areas such as southern Italy. ${ }^{5}$

Growth factors other than thyrotropin (TSH), and cytokines favor the development of diffuse and/or nodular goiter. ${ }^{7-9}$ However, only few studies have evaluated the role of different growth factors in the nodular variant of $\mathrm{HT}^{10,11}$

Recently, we reported the immunohistochemical expression of the hepatocyte growth factor (HGF) in HT-associated nodular goiter specimens and demonstrated that it was more frequent and intense than what observed in non-HT goiters. ${ }^{4}$ Upon binding to its specific tyrosinekinase receptor (HGF-R or c-met), HGF exerts mitogenic and anti-apoptotic activities in various cell types, including follicular thyroid cells. ${ }^{12-14}$ Previous studies demonstrated that HGF and cmet are expressed in hyperplastic nodules (but non in normal thyroid tissue) and are overexpressed in papillary thyroid carcinomas (PTC). ${ }^{15-18}$

Similarly to activation of the other ligand/ tyrosine kinase receptors, activation of the HGF/cmet signaling system recruits several intracellular effectors, including phosphatidylinositol 3kinase (PI3K), Ras, adaptators GRB2 and SHC, the docking protein Gabl, the member of the signal transducers and activators of transcription family STAT3, $\beta$ catenin and RHO. ${ }^{19-23}$ Such effectors are ubiquitous, as they are expressed in all human tissues, and trigger distinct biological events, i.e. growth, scattering and morphogenesis, in epithelial cells. ${ }^{21-29}$ Concerning thyroid oncology, expression of these ubiquitous effectors (for instance, STAT3, PI3K) has been investigated mainly in malignant thyroid tumors arising from the follicular epithelium, ${ }^{16,30-33}$ but rarely together with expression of HGF/c-met. ${ }^{16,30}$ The few data available on the expression of such molecules in thyroid nodules of HT patients are mainly focused on the possible association between $\mathrm{HT}$ and thyroid cancer. ${ }^{34}$ Larson and coworkers reported that the PI3K pathway components p-Akt, Akt1, and Akt2 were highly expressed in HT and HT-associated PTC, as well as in non-PTC, but not in the normal follicular epithelium. On this basis, they suggest that the PI3K/Akt pathway activation might represent a common molecular mechanism between the chronic autoimmune inflammation of thyroid and PTC. ${ }^{34}$

Moreover, two recent studies related PI3K
Correspondence: Maria Trovato,

Dipartimento di Patologia Umana, Padiglione D, Policlinico Universitario "G. Martino" via Consolare Valeria, 1 - 98125 Messina, Italy. Tel. +39.090.2212523; Fax: +39-090-2212523.

E-mail:mariatrovato@tin.it

Key words: HGF/c-met signaling; PI3K; RHO; Hashimoto's thyroiditis; thyroid nodules.

Acknowledgements: the authors thank Giuseppe Trombetta, Ph.D, for collaboration with his skillness.

Received for publication: 13 January 2010. Accepted for publication: 12 April 2010.

This work is licensed under a Creative Commons Attribution 3.0 License (by-nc 3.0).

(C) Copyright R.M. Rugger et al., 2010

Licensee PAGEPress, Italy

European Journal of Histochemistry 2010; 54:e24 doi:10.4081/ejh.2010.e24

expression/activation with the mechanisms of immunity response. ${ }^{35,36}$ It is well known that autoimmune thyroide diseases is related with the balance between Thelper types 1 and 2 (Th1 and Th2) responses, by an involvement of Tolllike receptors (TLR). ${ }^{1,237}$ The subunit p85 of PI3K participates, in this framework, in the ligation with TLR controlling the Th1/Th2 balance for an advantage of Thl cytokines. ${ }^{35}$ Moreover, PI3K regulatory subunits $\mathrm{p} 85$ regulates the motility of T and B lymphocytes. ${ }^{36}$

Here we evaluate the immunohistochemical expression of ligand/tyrosine kinase receptor pair HGF/c-met and three trasducers of activated tyrosine kinase receptors (STAT3, PI3K, RHO) in benign thyroid nodules, half of which developed in the context of background HT. To the best of our knowledge, the expression of these molecules has not been previously examined in HT.

\section{Materials and Methods}

\section{Tissues collection}

Fifty surgical thyroid specimens were retrieved from the files of our Pathology Department, while 5 normal thyroids (NT) were harvested at autopsy. All specimens were $4 \%$ formalin-fixed and paraffin-embedded. The 50 surgical specimens were from patients diagnosed and followed up at our Endocrine Unit and included benign nodular goiters (NG), of which 25 were associated with HT. In such patients, the diagnosis of HT was based on the currently accepted clinical, laboratory (circulating thyroid antibodies) and ultrasonographic criteria. All nodular lesions were studied along with the non- 
nodular tissue from the contralateral thyroid lobe (Table 1).

Hematoxylin-eosin-stained (H\&E) sections of each specimen were re-evaluated by the pathologists in order to confirm the HT diagnosis, evaluate the intra-glandular inflammatory lymphoid aggregates and catalogue the lesions by cytological morphology. HT was diagnosed using histopathologic criteria of Li Volsi. ${ }^{38}$

The lymphoid aggregates were categorized as previously reported. ${ }^{4,11}$ Briefly, aggregates made up of at least 150 lymphocytes and a variable number of plasma cells per high-power field, were considered as lymphoid aggregates and scored from 0 to $3(0=$ no lymphoid aggregate or at most one single, small lymphoid aggregate without germinal center in each section; $1=0$ occasional, usually small lymphoid aggregates with rare or absent germinal centers in each section; $2=$ several, usually mixed, small and large lymphoid aggregates with some germinal center in each section; $3=$ numerous, large lymphoid aggregates with frequent germinal centers in each section).

Cellular morphology was classified according to the nuclear and cytoplasm features at light microscopy, as previously reported. ${ }^{4,39}$ Based on these morphological features, the thyrocytes of each lesion were classified into three different cellular types: i) dark nucleus and eosinophilic cytoplasm (DN-EC); ii) dark nucleus and oncocytic cytoplasm (DN-OC or Hurtle cells); iii) clear nucleus and eosinophilic cytoplasm (CN-EC) (Table 1).

\section{Immunohistochemistry}

The 55 blocks were cut into serial sections of five-micrometers each. Immunohistochemistry was performed, separately, using rabbit polyclonal antibodies against HGF- $\alpha$ (H-145, working dilution (w.d.) 1:100), c-met (p140 anti h-met, w.d. 1:100) and STAT3 (h-190, w.d.1:100), all three purchased from Santa Cruz Biotechnology, Inc. (Santa Cruz, CA, USA); a mouse monoclonal antibody against PI3K p85 $\alpha$ (B-9, w.d. 1:200), purchased from Santa Cruz Biotechnology, Inc. (Santa Cruz, CA, USA), and a rabbit monoclonal antibody against RHO (Y486, w.d.1:100), purchased from Abcam plc., Cambridge, UK. Tissue sections were deparaffinized in xylene and rehydrated in alcohol. Next, the endogenous biotin was inactivated by the addition of a $0.05 \%$ (v/v) solution of streptavidin in phosphate-buffered saline (PBS), and the endogenous peroxidase activity was quenched by adding a $0.3 \%(\mathrm{v} / \mathrm{v})$ solution of $3 \% \mathrm{H}_{2} \mathrm{O}_{2} /$ methanol for $30 \mathrm{~min}$. Staining was obtained with the LSAB system (kit from Dako, Carpinteria, CA, USA). 3,3'diaminobenzidine (DAB, Sigma) activated with $0.05 \%$ hydrogen peroxide was used to develop the end reactions. Sections were counterstained with Mayer's hematoxylin, dehydrated and mounted.

Table 1. Expression of HGF, c-met, PI3K and RHO on epithelial and stromal cells in a series of 25 colloid nodular goiters (NGs) and of 25 nodular Hashimoto's thyroditis (HT) examined along with the corresponding extra-nodular thyroid tissue.

\begin{tabular}{|c|c|c|c|c|c|c|}
\hline \multirow{2}{*}{$\begin{array}{l}\text { Thyroid lesions } \\
\text { cases }\end{array}$} & \multirow{2}{*}{$\begin{array}{l}\text { Positive } \\
\text { cases }\end{array}$} & \multirow{2}{*}{$\begin{array}{l}\text { Reactive* } \\
\text { cells* }\end{array}$} & \multicolumn{4}{|c|}{ Percentage of positive cells (mean $\pm \mathrm{SD}$ ) } \\
\hline & & & HGF & c-met & PI3K & RHO \\
\hline $\begin{array}{l}\text { Colloid nodular } \\
\text { goiters (NGs, } n=25 \text { ) }\end{array}$ & $7(28 \%)$ & $\begin{array}{c}\text { Epithelial (DN-EC) } \\
\text { stromal }\end{array}$ & $\begin{array}{c}0 \\
9 \pm 2\end{array}$ & $\begin{array}{c}4 \pm 2 \\
0\end{array}$ & $\begin{array}{c}0 \\
7 \pm 3\end{array}$ & $\begin{array}{c}0 \\
8 \pm 3\end{array}$ \\
\hline $\begin{array}{l}\text { NGs associated } \\
\text { with HT }(\mathrm{n}=25)\end{array}$ & 25 (100\%) & $\begin{array}{c}\text { Epithelial (DN-EC) } \\
\text { stromal }\end{array}$ & $\begin{array}{c}0 \\
12 \pm 8\end{array}$ & $\begin{array}{c}4 \pm 2 \\
0\end{array}$ & $\begin{array}{c}0 \\
8 \pm 4\end{array}$ & $\begin{array}{c}0 \\
7 \pm 3\end{array}$ \\
\hline $\begin{array}{l}\text { Extra-nodular thyroid } \\
\text { tissue of HT }(n=25)\end{array}$ & $25(100 \%)$ & $\begin{array}{c}\text { Epithelial } \\
\text { DN-EC } \\
\text { DN-OC } \\
\text { CN-EC } \\
\text { stromal }\end{array}$ & $\begin{array}{c}58 \pm 20 \\
24 \pm 25 \\
21 \pm 13 \\
11 \pm 8\end{array}$ & $\begin{array}{c}19 \pm 5 \\
9 \pm 8 \\
8 \pm 5 \\
0\end{array}$ & $\begin{array}{c}25 \pm 8 \\
0 \\
0 \\
8 \pm 4\end{array}$ & $\begin{array}{c}0 \\
0 \\
0 \\
8 \pm 3\end{array}$ \\
\hline
\end{tabular}

*Thyroid lesions were catalogued by cytological morphology of thyrocytes based on nuclear and cytoplasm features at light microscopy, ${ }^{439}$ as detailed in Material and Methods. Based on these morphological features, the cells of each lesion were categorized as: i) dark nucleus and eosinophilic cytoplasm (DN-EC); ii) dark nucleus and oncocytic cytoplasm (DN-OC); iii) clear nucleus and eosinophilic cytoplasm (CN-EC). ${ }^{\circ}$ The count of the reactive epithelial and stromal cells was based on evaluation of 1000 cells/case, using a 50X magnification. Values pertaining to stromal cells are typed in italics.

Specificity of the antibody binding was assessed by omitting the primary antiserum or by replacing the primary antiserum with normal rabbit or mouse serum. In each of these conditions, no staining was evident. In addition, an immunoabsorption test was performed to confirm the specific immunoreactivity of each antibody. Specimens of normal tissues of bladder and liver were used as positive controls for HGF and c-met immunoreaction, respectively. Positive controls for STAT3, PI3K and RHO immonoreaction were performed by using specimens of lung, breast and liver carcinomas, respectively. The evaluation of the results was based on: i) number of positive cases; ii) number of reactive epithelial and stromal cells per case, based on counting 1000 cells/case at 50X magnification; iii) subcellular location of the staining: membrane, cytoplasm and nucleus; iv) staining grade using a semiquantitave score system from 0 to $4+(0$, absent; $1+$, weak but distinct; $2+$, moderate; $3+$, intense; $4+$, very intense). Histological and immunohistochemical evaluations were done twice and blindly by two pathologists (M.T., G.B.) with an inter-observer concordance of nearly $100 \%$. Where minimal inter-observer discrepancies were present, data were averaged.

\section{Statistical analysis}

Data were tested for normal distribution and variance (mean $\pm \mathrm{SD}$ ) and analyzed by the twotailed Student's t-test, ANOVA and $\chi^{2}$ test with Yates' correction for continuity, when appropriate. The association between two variables was analyzed by the linear regression analysis. The level of statistical significance was always set at $\mathrm{P}<0.05$.

\section{Results}

\section{Histopathology and cellular morphology}

All the 50 benign NGs showed the histological features of colloid nodules characterized by either large or small colloid-filled follicles built by cells with small flat or cubic shape. Instead, cellular hallmarks of these lesions were the epithelial follicular cells with DN-EC features, even if in most cases of HT-associated NGs, DN-OC cells and seldom CN-EC cells too were observed (Table 1). The predominant cellular type in HT showed features of DN-EC cells. Intra-nodular lymphoid aggregates were absent (grade 0 ) in all 50 NGs. Extra-nodular lymphoid aggregates were the main histological evidence of HT. These aggregate were graded as 1 (10/25 or 40\%), 2 (12/25 or $48 \%)$ or $3(3 / 25$ or $12 \%)$. As previously specified into the Materials and Methods paragraph, the 25 HT specimens were from patients diagnosed at our Endocrine Unit, and all of them have circulating anti-thyroid antibodies.

\section{Immunohistochemistry}

Illustrative immunohistochemistry for HGF, cmet, PI3K and RHO is presented in Figure 1. No expression of HGF, c-met, STAT3, PI3K and RHO was detected in normal thyroid tissue, namely the control normal thyroids and the contralateral lobe to the 25 NGs not associated with HT. Similarly, no immunostaining for STAT3 was observed in all nodular lesions.

\section{Expressions of HGF/ c-met/PI3K/RHO in NGs}

The ligand/tyrosine kinase receptor pair HGF/c-met and the two trasducers PI3K and RHO were expressed in NGs, regardless of association 
with HT. However, significant differences in the distribution of immunoreactions could be detected by comparing the NGs arising in the context of HT with the HT-unassociated NGs. The expression of HGF, c-met, PI3K and RHO was detected more frequently in the former than in the latter nodules $(25 / 25$ or $100 \%$ vs $7 / 25$ or $28 \% ; \mathrm{P}<0.001)$ (Table 1). However, there were no differences in the localization of immunostaining between the two types of lesions. Thus, in all 32 reactive NGs, HGF, PI3K and RHO expressions were only stromal (fibroblasts and endothelial cells) and cytoplasmic, while the localization of c-met was consistently epithelial (thyrocyes), both membranous and cytoplasmic. The percentage of reactive cells and the intensity of their immunoreactivity were similar in both types of NGs. Thus, immunoreaction for HGF, PI3K and RHO concerned $5-10 \%$ of stromal cells, and intensity of immunostaining was weak or moderate. In the same 32 nodules, a weak c-met immunoreaction was restricted to $3-8 \%$ of thyrocytes (Table 1). The c-met reactive epithelial cells of all 32 nodules showed the cytological features of DN-EC cells.

\section{Expressions of HGF/ c-met/ STAT3/PI3-}

$\mathrm{K} / \mathrm{RHO}$ in the non-nodular tissue of $\mathrm{HT}$

Immunoreactions for HGF, c-met, PI3K and RHO were also observed in the non-nodular tissue of HT specimens, but their expression differed from what observed in NGs (Table 1).

Indeed, while stromal expression of HGF, PI3K and RHO matched the corresponding stromal expression in NGs, the cytoplasm of thyrocytes also expressed HGF and PI3K, an epithelial immunoreactivity that was absent in all NGs. HGF and c-met were detected in thyrocytes with DN-EC, DN-OC and CN-EC features, while PI3K was expressed by epithelial follicular cells with the sole DN-EC features (10-35\%) (Table 1 and Figure 1). Hence, thyrocytes with DN-EC features expressed the three molecules (HGF, c-met and PI3K), while both DN-OC and CN-EC thyrocytes expressed only HGF and its receptor c-met. Among thyrocytes immunoreacting for both HGF and c-met, the major proportion of HGF and cmet +ve cells showed DN-EC features $(\mathrm{HGF}+\mathrm{ve}$ DN-EC cells: $58 \pm 20 \%$, range 30 to $80 \%$; c-met +ve DN-EC cells: $19 \pm 5 \%$, range 10 to $25 \% ; \mathrm{P}<0.001$ vs the corresponding percentages of $\mathrm{DN}-\mathrm{OC}$ and CN-EC cells) (Table 1). Moreover, all HT lesions showed an intense stromal immunostaining for HGF (which concerned $5-40 \%$ of cells) as well as PI3K and RHO (5-15\% of cells) (Table 1). Finally, the staining grade observed for the four proteins in HT was higher than that observed in NGs, because it was moderate to very intense as compared with weak to moderate (data non shown).

Comparing the proportion of DN-EC cells expressing the HGF, c-met and PI3K with the grade of lymphoid aggregates, a positive correlation was observed for the three protein [HGF:
Table 2. Expression of HGF, c-met, PI3K and RHO on epithelial and stromal cells in the extra-nodular tissue of the 25 cases of Hashimoto's thyroditis (HT), split into two subgroups ( $A$ and $B$ ) according to the presence or absence of germinal centers in the lymphoid infiltrate*.

\begin{tabular}{|c|c|c|c|c|c|c|}
\hline \multirow{2}{*}{ HT (n=25) } & \multirow{2}{*}{$\begin{array}{l}\text { Positive } \\
\text { cases }\end{array}$} & \multirow{2}{*}{$\begin{array}{c}\text { Reactive } \\
\text { cells }^{\circ}\end{array}$} & \multicolumn{4}{|c|}{ Percentage of positive cells (mean \pm SD) } \\
\hline & & & HGF & c-met & PI3K & RHO \\
\hline $\begin{array}{l}\text { Group A } \\
\text { (Lymphoid } \\
\text { aggregate grade 1) } \\
(\mathrm{n}=10)\end{array}$ & ${ }^{\sharp 1} 1-10$ & $\begin{array}{c}\text { epithelial } \\
\text { DN-EC } \\
\text { DN-OC } \\
\text { CN-EC } \\
\text { stromal }\end{array}$ & $\begin{array}{c}37 \pm 8 \\
4 \pm 8 \\
14 \pm 12 \\
15 \pm 11\end{array}$ & $\begin{array}{c}14 \pm 4 \\
2 \pm 4 \\
5 \pm 4 \\
0\end{array}$ & $\begin{array}{c}17 \pm 4 \\
0 \\
0 \\
9 \pm 4\end{array}$ & $\begin{array}{c}0 \\
0 \\
0 \\
8 \pm 3\end{array}$ \\
\hline $\begin{array}{l}\text { Group B } \\
\text { (Lymphoid } \\
\text { aggregate grade } \\
2 \text { and } 3)(n=15)\end{array}$ & $" 11-25$ & $\begin{array}{l}\text { epithelial } \\
\text { DN-EC } \\
\text { DN-OC } \\
\text { CN-EC }\end{array}$ & $\begin{array}{l}71 \pm 11 \\
38 \pm 22 \\
26 \pm 13\end{array}$ & $\begin{array}{l}22 \pm 2 \\
13 \pm 7 \\
10 \pm 4\end{array}$ & $\begin{array}{c}30 \pm 5 \\
0 \\
0\end{array}$ & $\begin{array}{l}0 \\
0 \\
0\end{array}$ \\
\hline & & stromal & $7 \pm 5$ & $\begin{array}{c}0.001 \mathrm{vs} \\
0 \\
0.025 \mathrm{vs}\end{array}$ & $\begin{array}{c}\text { up A } \\
8 \pm 3 \\
\text { up A }\end{array}$ & $7 \pm 2$ \\
\hline
\end{tabular}

*Lymphoid aggregates were scored from 0 to 3 ( $0=$ no lymphoid aggregate; $1=0$ ccasional lymphoid aggregates with rare or absent germinal centers in each section; $2=$ several lymphoid aggregates with some germinal center; $3=$ numerous lymphoid aggregates with frequent germinal centers), as detailed in Material and Methods. ${ }^{\circ}$ Thyroid follicular cells were categorized as: i) dark nucleus and eosinophilic cytoplasm (DN-EC); ii) dark nucleus and oncocytic cytoplasm (DN-OC); iii) clear nucleus and eosinophilic cytoplasm (CN-EC), based on nuclear and cytoplasm features at light microscopy, ${ }^{439}$ as detailed in Material and Methods. \#The count of the reactive epithelial and stromal cells was based on evaluation of 1000 cells/case, using a 50X magnification. Values pertaining to stromal cells are typed in italics.
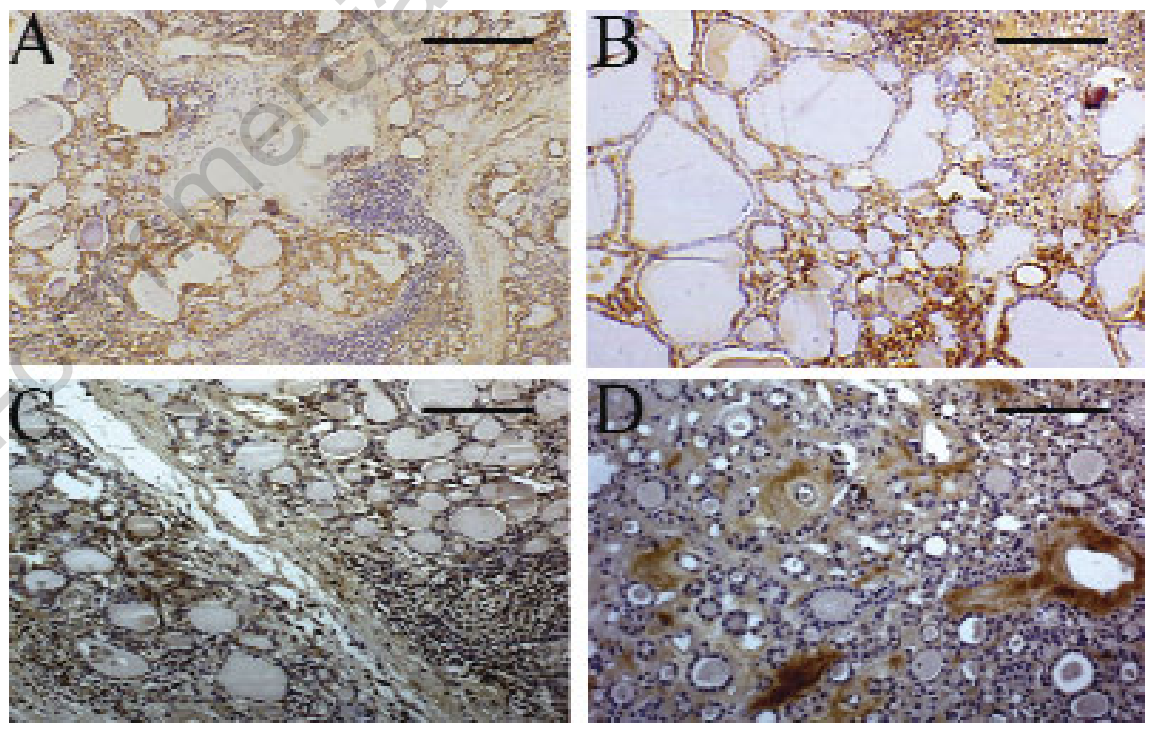

Figure 1. HGF, c-met, PI3K and RHO immunostaining in specimens of Hashimoto's thyroditis (HT) and nodular goiters (NGs). Panel A: very intense HGF immunoreaction in a sample of HT with lymphoid aggregates defined as grade 2. The HGF immunostaining is located on the cytoplasm of thyrocytes (brown deposits) showing morphological characteristics of DN-EC cells. Note the absence of HGF reactivity in the lymphocytes (original magnification: X 150, reference bar $=133 \mu \mathrm{m}$ ). Panel B: intense c-met immunostaining in a sample of HT with grade 2 lymphoid aggregates. The c-met reaction is observed on the membrane and cytoplasm (brown deposits) of follicular DN-EC cells. No c-met reactivity is detected in lymphocytes (original magnification: $X 150$, reference bar $=133 \mu \mathrm{m}$ ). Panel C: moderate PI3K immunoreaction in a sample of HT with grade 2 lymphoid aggregates. The immunoreaction is located in the cytoplasm of epithelial DN-EC cells (brown deposits). Note the absence of PI3K reactivity in lymphocytes (original magnification: X 130, reference bar $=153 \mu \mathrm{m}$ ). Panel D: moderate RHO immunoreaction in a sample of NG not associated with HT. The RHO immunostaining is located on the cytoplasm of stromal cells (original magnification: X 130, reference bar $=153 \mu \mathrm{m}$ ). 
$\mathrm{r}=0.96, \mathrm{P}=0.17$; c-met: $\mathrm{r}=0.91, \mathrm{P}=0.22 ; \mathrm{PI} 3 \mathrm{~K}$ : $\mathrm{r}=0.94, \mathrm{P}=0.27$ ] (Figure 2). Moreover, by splitting the HT cases into two subgroups, according to the presence or absence of germinal centers in the lymphocytic infiltrate (Table 2), we found that the expression of c-met, PI3K and especially HGF in epithelial cells was much more pronounced in the 15 cases with presence of germinal centers (lymphocytic infiltrate grade 2 and 3 ), as compared to the 10 cases with lymphocytic infiltrate grade 1, in which the lymphoid aggregates were occasional with rare or absent germinal centers $(\mathrm{P}<0.001)$. This observation reinforces the hypothesis that the expression of such molecules in HT may be regulated by lymphoid infiltrate.

\section{Discussion}

True nodular lesions frequently arise in the context of HT, as consequence of a hyperplastic follicular growth, which leads to an increase in number and size of follicles. Several growth factors and cytokines are known to cooperate with TSH in thyroid nodular growth, but few data are available on their expression in nodular lesions associated with $\mathrm{HT}^{10,11}$

In the present study, we report that the expression of the HGF/c-met system is associated with that of the tyrosine kinase receptors trasducers PI3K and RHO in both NGs and HT lesions, while the normal thyroids do not express any. These findings are in line with the known ability of HGF to induce cellular growth, as well as with our previous reports in which we observed that HGF and its receptor c-met are expressed in goitrous samples as well as in thyroid tissues with HT, but undetectable in normal thyroid tissue., ${ }^{4,15}$ Our present study offers some new knowledge.

First, we demonstrated the expression of the tyrosine kinase receptors trasducers $\mathrm{PI} 3 \mathrm{~K}$ and RHO in both HNs and HT lesions expressing the $\mathrm{HGF} / \mathrm{cmet}$ system, but we detected a more frequent expression of HGF, c-met, PI3K and RHO in the NGs associated with HT, either with scarce lymphoid aggregates or with germinal centers, as compared to non HT-associated NGs.

Another major result of our study is the different localization of HGF and PI3K expressions in NGs and HT, even when occurring in the same thyroid gland. In the NGs, approximately $10 \%$ of stromal cells expressed HGF, thus providing the ligand for a paracrine interaction with the c-met expressed on a limited number of epithelial cells. However, this possible interaction was not accompanied by the epithelial expression of any of the three trasducers investigated (STAT3, PI3K and RHO). In fact, both PI3K and RHO expression was restricted to approximately $8 \%$ of the stromal cells of NGs regardless of coexisting HT. Therefore, the cellular localization of such mole-

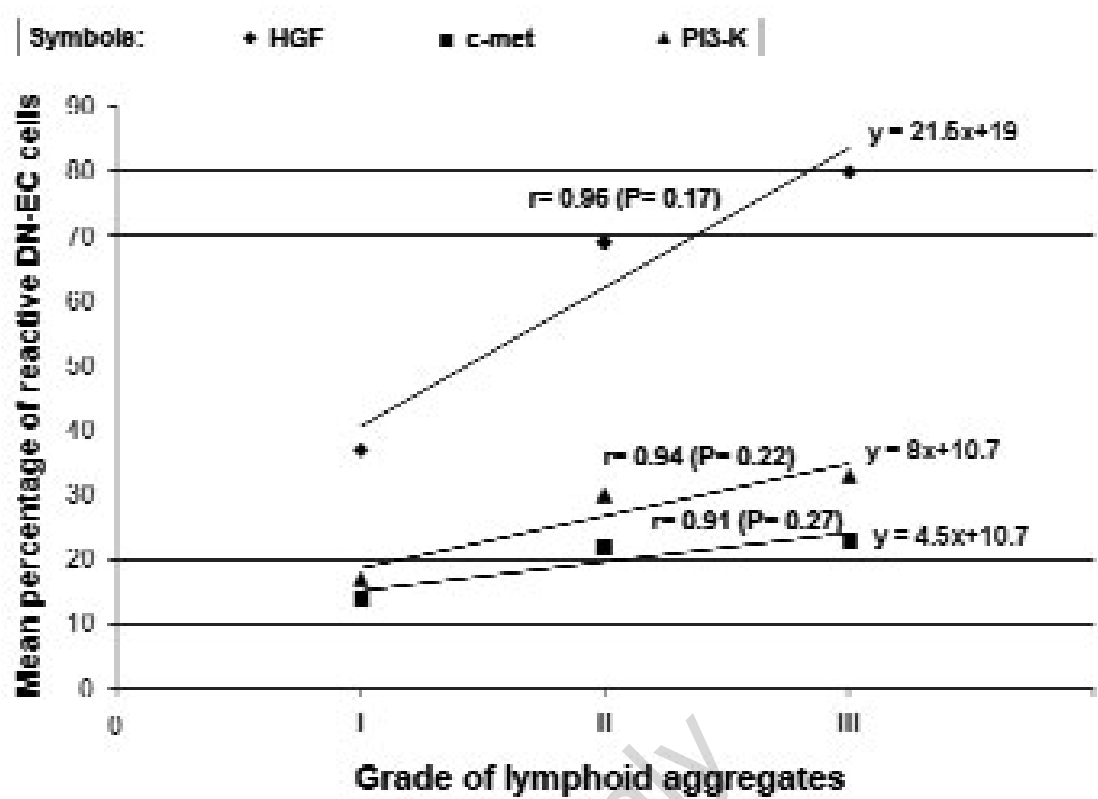

Figure 2. Positive correlation between HGF, c-met and PI3K expressions and the grade of lymphoid aggregates, which is scored as indicated in Materials and Methods.

cules seems to be independent from the HT lesion associated with the nodular goiter. Further, the expression of PI3K and RHO in stromal cells appears to be independent from activation of the HGF/c-met signaling in this cellular type, since there was no stromal expression of cmet. In HT, HGF and PI3K immunoreactions involved both stromal and epithelial cells, raising the possibility of c-met activation through an autocrine loop with subsequent involvement of PI3K.

The characterization of the follicular epithelial cells of HT based on the nuclear and cytoplasmic features allowed us to identify the follicular cells with DN-EC features as the cellular type specifically involved in the epithelial pathway of HGF, cmet and PI3K. Indeed, the epithelial co-expression of HGF, c-met and PI3K was observed only in such cells, while the other reactive epithelial cellular types expressed only the ligand and the receptor.

These evidences suggest that the HGF/c-met system may play a role in the development of nodular goiter, and more specifically in the goitrous growth of HT. Moreover, these data suggest that HGF acts as a goitrous growth factor in a paracrine fashion in HT-associated or not HTassociated NGs, but both in a paracrine and autocrine fashion in HT. The expression of the three molecules (c-met, PI3K and especially HGF) is much more pronounced in nodules associated with diffuse HT, proved by the presence of germinal centers, rather than in HT with scarce lymphoid aggregates. In those latter, however, the expression of the investigated molecules is significantly higher with respect to non HT-NGs.

Finally, the positive correlation we found between the immunoistochemical expression of HGF, c-met and PI3K in DN-EC cells and the lymphoid aggregates lead us to postulate that HGF, cmet and PI3K signals may have a role also in the mechanism of thyroid autoimmunity, as supported by two recent studies relating PI3K expression/activation with the mechanisms of the immunity response.$^{35,36}$ In this way, the expression of PI3K in DN-EC thyrocytes could be involved in the cascade of immune events, such as in presenting antigens and recalling up lymphocytes.

\section{References}

1. Weetman AP. Autoimmune thyroid disease: propagation and progression. Eur J Endocrinol 2003;148:1-9.

2. Weetman AP. Autoimmune thyroid disease. Autoimmunity 2004;37:337-40.

3. Rago T, Chiovato L, Grasso L, Pinchera A Vitti P. Thyroid ultrasonography as a tool for detecting thyroid autoimmune diseases and predicting thyroid dysfunction in apparently healthy subjects. J Endocrinol Invest 2001; 24:763-9.

4. Ruggeri RM, Sciacchitano S, Trimarchi F, Barresi G, Trovato M. Expression of hepatocyte growth factor in Hashimoto's thyroiditis with nodular lesions. Eur J Histochem 2007;51:193-8.

5. Benvenga S, Trimarchi F. Changed presentation of Hashimoto's thyroiditis in NorthEastern Sicily and Calabria (Southern Italy) based on a 31-year experience. Thyroid 
2008;18:429-41.

6. Ruggeri RM, Sciacchitano S, Vitale A, Cardelli P, Galletti M, Vitarelli E et al. Serum Hepatocyte Growth Factor (HGF) is increased in Hashimoto's thyroiditis either or nor associated with nodular goiter as compared with healthy non-goitrous individuals. J Endocrinol Invest 2009;32: 465-9.

7. Bidey SP, Hill DJ, Eggo MC. Growth factors and goitrogenesis. J Endocrinol 1999;160: 321-32.

8. Kimura T, Van Keymeulen A, Golstein J, Fusco A, Dumont JE, Roger PP. Regulation of thyroid cell proliferation by TSH and other factors: a critical evaluation of in vitro models. Endocr Rev 2001;22:631-56.

9. Eggo MC, Quiney VM, Campbell S. Local factors regulating growth and function of human thyroid cells in vitro and in vivo. Mol Cell Endocrinol 2003;213:47-58.

10. Ruggeri RM, Villari D, Simone A, Scarfi R, Attard M, Orlandi F et al. Co-expression of interleukin-6 (IL-6) and interleukin-6 receptor (IL-6R) in thyroid nodules is associated with co-expression of CD30 ligand/CD30 receptor. J Endocrinol Invest 2002;25:959-66.

11. Ruggeri RM, Barresi G, Sciacchitano S, Trimarchi F, Benvenga S, Trovato $\mathrm{M}$. Immunoexpression of the CD30 ligand/ CD30 and IL-6/IL-6R signals in thyroid autoimmune diseases. Histol Histopathol 2006;21:249-56.

12. Bottaro DP, Rubin JS, Faletto D, Chan AM, Kmiecik TE, Vande Woude GF et al. Identification of the hepatocyte growth factor receptor as the c-met proto-oncogene product. Science 1991;251:802-4.

13. Weidner KM, Sachs M, Birchmeier W. The Met receptor tyrosine kinase transduces motility, proliferation, and morphogenic signals of scatter factor/hepatocyte growth factor in epithelial cells. J Cell Biol 1993; 121:145-54.

14. Eccles N, Ivan M, Wynford-Thomas D. Mitogenic stimulation of normal and oncogene transformed human thyroid epithelial cells by hepatocyte growth factor. Mol Cell Endocrinol 1996;117:247-51.

15. Trovato M, Villari D, Bartolone L, Spinella S, Simone A, Violi MA et al. Expression of the hepatocyte growth factor and c-met in normal thyroid, non-neoplastic, and neoplastic nodules. Thyroid 1998;8:125-31.

16. Trovato M, Grosso M, Vitarelli E, Ruggeri RM, Alesci S, Trimarchi F et al. Distinctive expression of STAT3 in papillary thyroid carcinomas and a subset of follicular adenomas. Histol Histopathol 2003;18:393-9.

17. Scarpino S, D'Alena FC, Di Napoli A, Ballarini F, Prat M, Ruco LP. Papillary carcinoma of the thyroid: evidence for a role for hepatocyte growth factor (HGF) in promot- ing tumour angiogenesis. J Pathol 2003; 199:243-50.

18. Mineo R, Costantino A, Frasca F, Sciacca L, Russo S, Vigneri $R$ et al. Activation of the hepatocyte growth factor (HGF)-Met system in papillary thyroid cancer: biological effects of HGF in thyroid cancer cells depend on Met expression levels. Endocrinology 2004;145: 4355-65.

19. Graziani A, Gramaglia D, Cantley LC, Comoglio PM. The tyrosine-phosphorylated hepatocyte growth factor/scatter factor receptor associates with phosphatidylinositol 3-kinase. J Biol Chem 1991;266: 2208790.

20. Ponzetto C, Zhen Z, Audero E, Maina F, Bardelli A, Basile ML et al. Specific uncoupling of GRB2 from the met receptor. Differential effects on transformation and motility. J Biol Chem 1996;271:14119-23.

21. Boccaccio C, Ando M, Tamagnone L, Bardelli A, Michieli P, Battistini C et al. Induction of epithelial tubules by growth factor HGF depends on the STAT pathway. Nature 1998;391: 285-8.

22. Okano J, Shiota G, Matsumoto K, Yasui S, Kurimasa A, Hisatome I et al. Hepatocyte growth factor exerts a proliferative effect on oval cells through the PI3K/AKT signaling pathway. Biochem Biophys Res Commun 2003;309: 298-304.

23. Vandeput F, Perpete S, Coulonval K, Lamy F, Dumont JE. Role of the different mitogenactivated protein kinase subfamilies in the stimulation of dog and human thyroid epithelial cell proliferation by cyclic adenosine 5'-monophosphate and growth factors. Endocrinology 2003;144:1341-9.

24. Ridley AJ, Comoglio PM, Hall A. Regulation of scatter factor/hepatocyte growth factor responses by Ras, Rac, and Rho in MDCK cells. Mol Cell Biol 1995;15:1110-22.

25. Potempa S, Ridley AJ. Activation of both MAP kinase and phosphatidylinositide 3-kinase by Ras is required for hepatocyte growth factor/scatter factor-induced adherens junction disassembly. Mol Biol Cell 1998;9:2185-200.

26. Bardelli A, Basile ML, Audero E, Giordano S, Wennström S, Ménard S et al. Concomitant activation of pathways downstream of Grb2 and PI 3-kinase is required for MET-mediated metastasis. Oncogene 1999;18:1139-46.

27. Kodama A, Matozaki T, Fukuhara A, Kikyo M, Ichihashi M, Takai Y. Involvement of an SHP2-Rho small G protein pathway in hepatocyte growth factor/scatter factor-induced cell scattering. Mol Biol Cell 2000; 11:2565-75.

28. Royal I, Lamarche-Vane N, Lamorte L, Kaibuchi K, Park M. Activation of cdc42, rac, PAK, and rho-kinase in response to hepatocyte growth factor differentially regulates epithelial cell colony spreading and dissocia- tion. Mol Biol Cell 2000;11:1709-25.

29. Coulonval K, Vandeput F, Stein RC, Kozma SC, Lamy F, Dumont JE. Phosphatidylinositol 3-kinase, protein kinase B and ribosomal S6 kinases in the stimulation of thyroid epithelial cell proliferation by cAMP and growth factors in the presence of insulin. Biochem $\mathrm{J}$ 2000;348:351-8.

30. Liu Z, Hou P, Ji M, Guan H, Studeman K, Jensen $\mathrm{K}$ et al. Highly prevalent genetic alterations in receptor tyrosine kinases and phosphatidylinositol 3-Kinase/Akt and mitogen-activated protein kinase pathways in anaplastic and follicular thyroid cancers. J Clin Endocrinol Metab 2008;93:3106-16.

31. Paes JE, Ringel MD. Dysregulation of the phosphatidylinositol 3-kinase pathway in thyroid neoplasia. Endocrinol Metab Clin North Am 2008;37:375-87.

32. Santarpia L, El-Naggar AK, Cote GJ, Myers JN, Sherman SI. Phosphatidylinositol 3kinase/akt and ras/raf-mitogen-activated protein kinase pathway mutations in anaplastic thyroid cancer. J Clin Endocrinol Metab 2008;93:278-84.

33. Wang Y, Hou P, Yu H, Wang W, Ji M, Zhao S et al. High prevalence and mutual exclusivity of genetic alterations in the phosphatidylinositol-3-kinase/AKT pathway in thyroid tumors. J Clin Endocrinol Metab 2007;92: 2387-90.

34. Larson SD, Jackson LN, Riall TS, Uchida T, Thomas RP, Qiu S et al. Increased incidence of well-differentiated thyroid cancer associated with Hashimoto's thyroiditis and the role of the PI3K/Akt pathway. J Am Coll Surg 2007;204:764-73.

35. Hazeki K, Nigorikawa K, Hazeki 0. Role of phosphoinositide 3-kinase in innate immunity. Biol Pharm Bull 2007;30:1617-23.

36. Matheu MP, Deane JA, Parker I, Fruman DA, Cahalan MD. Class IA phosphoinositide 3kinase modulates basal lymphocyte motility in the lymph node. J Immunol 2007;179: 2261-9.

37. Caturegli P, Kimura H, Rocchi R, Rose NR. Autoimmune thyroid diseases. Curr Opin Rheumatol 2007;19:44-8.

38. Li Volsi V. Lymphocytes in the thyroid. In: Li Volsi V. ed. Surgical Pathology of the Thyroid. W.B. Saunders Company, Philadelphia, 1990, PP. 68-97.

39. Trovato M, Ulivieri A, Dominici R, Ruggeri RM, Vitarelli E, Benvenga $S$ et al. Clinicopathological significance of cell-type-specific loss of heterozygosity on chromosome $7 \mathrm{q} 21$ : analysis of 318 microdissected thyroid lesions. Endocr Relat Cancer 2004; 11: 36576 . 